\title{
Slow-Twitch Motor Unit
}

National Cancer Institute

\section{Source}

National Cancer Institute. Slow-Twitch Motor Unit. NCI Thesaurus. Code C33564.

A type of motor unit, comprising a group of individual muscle fibers that are activated by a single motor neuron, that has low contraction strength, high endurance, and is dependent on aerobic metabolism for energy. 